\title{
An Experimental Study of Velocity-Saturation Relationships in Volcanic Rocks
}

\author{
Zhidi Liu ${ }^{*}$ and Jingzhou Zhao
}

School of Earth Sciences and Engineering, Xi'an Shiyou University, Xi'an 710065, China

\begin{abstract}
In this paper, experiments are carried out under different pressures and water saturations using core samples of volcanic rocks from the Junggar Basin in China to understand how water saturation affects P- and S-wave velocities. The results show that water saturated rocks exhibit significantly higher $\mathrm{P}$ - and $\mathrm{S}$-wave velocities than gas saturated rocks. In addition, the $\mathrm{P}$ - and S-wave velocity ratio declines with increasing water saturation. Furthermore, a P- and S-wave velocity ratio vs. resistivity cross plot is created to identify gas reservoirs in the volcanic rocks in the Junggar Basin.
\end{abstract}

Keywords: Gas recognition, P-wave and S-wave velocity, volcanic rock, water saturation.

\section{INTRODUCTION}

The intrinsic relationship between the properties of pore fluids in formations and the physical properties of rocks is a key factor in hydrocarbon zone assessment and production, so it is extremely important to study the effects of changing pore water contents on the wave velocities of rocks. To understand the characteristics of P- wave velocity (Vp) and Swave velocity (Vs) in water-saturated rocks, Gassmann (1951) conducted a series of studies and found that pore fluids increase the P-wave velocity of rocks but slightly decreases the S-wave velocity [1]. Using high frequency acoustic waves to measure consolidated rocks, Murphy et al (1993) discovered that the P-wave velocity declines with increasing gas saturation in rock pores [2]. Based on dolomite and sandstone specimen lab experiments, Zhang et al (1995) investigated the relationship between the velocity and amplitude of P-waves and water saturation [3]. They discovered that a basket of gas in rock may decelerate the acoustic velocity in a short period; the P-wave velocity remains almost unchanged when the water saturation is greater than $90 \%$, and the acoustic velocity increases drastically when the water saturation is less than 90\%. Chardac et al. (2003) adopted a cross plot of the P- and S-wave velocity ratio $(\mathrm{Vp} / \mathrm{Vs})$ vs. the P-wave offset time to identify the characteristics of strata that contains oil and gas $[4,5]$. This differs from the previous methods, although they have essentially made use of $\mathrm{Vp} / \mathrm{Vs}$.

However, few experiments have been performed on Pand $\mathrm{S}$-waves in water-saturated volcanic rocks. In this paper, we select a batch of core samples of volcanic rocks from the Junggar Basin in China. Experiments are performed to determine the $\mathrm{Vp}$ and $\mathrm{Vs}$ of these specimens under different pressures and water saturations. We discuss the application of $\mathrm{Vp} / \mathrm{Vs}$ to identify gas-water formation in volcanic rocks.

*Address correspondence to this author at the School of Earth Sciences and Engineering, Xi'an Shiyou University, Xi'an, China;

Tel: +0086-15529269858; E-mail: liuzhidi@xsyu.edu.cn

\section{GEOLOGICAL CHARACTERISTICS OF THE WORK AREA}

In this paper, the experimental study of wells is conducted in the Dx area, which is located in the central-western Dinan bulge in the Junggar Basin, China (Fig. 1). The Dx area extends to the east Karamaly Mountain, connects to the west Shixi bulge, approaches the south Dongdaohai riding, and connects to the north Dishuiquan riding. The Carboniferous volcanic rocks in the Dx area include volcanic clastic rocks, volcanic lava, subvolcanic rocks and a few volcanic sedimentary rocks, and the volcanic rock types range from basic to acidic. The subvolcanic rock types are mainly monzonitic porphyry and granite porphyry. The volcano lava types are mainly basalt and rhyolite with minor andesites. The volcanic clastic rocks are mainly volcanic tuffs and breccia volcanics. The spatial distribution is roughly divided into northwestern, central and southeastern areas. The northeast displays a banded distribution range and shows obvious regional segmentation. On the whole, it transitions from basic to acidic from the northwest to southeast.

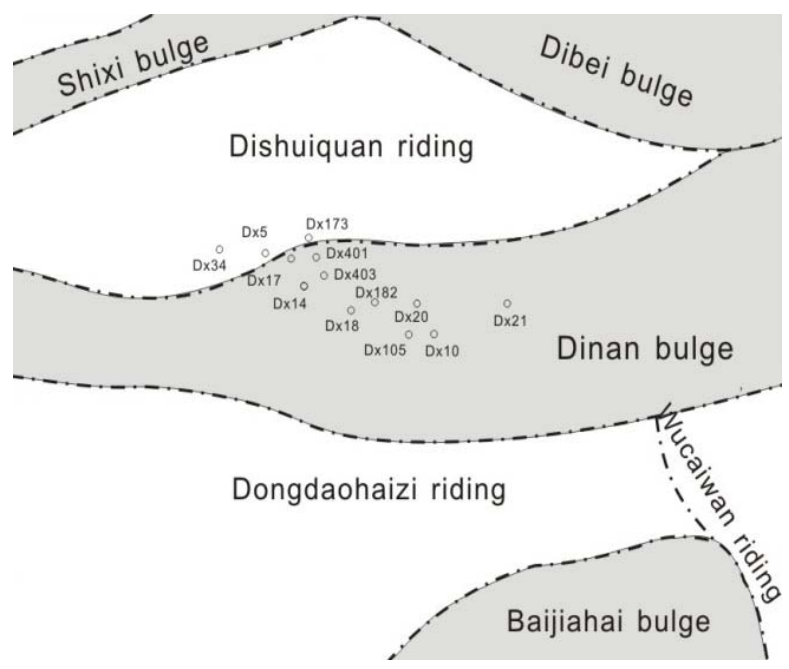

Fig. (1). The location map of the basin and the well. 


\section{THEORY OF VP/VS AND WATER SATURATION}

Gassmann (1951) proposed a formula for rock volume modulus calculation - Gassmann's Equation. The equation describes the relationship among the rock volume modulus, porosity, volume modulus of pore fluids, volume modulus of the rock matrix and volume modulus of rock-forming minerals.

$\frac{k_{s a t}}{k_{o}-k_{s a t}}=\frac{k_{d r y}}{k_{o}-k_{d r y}}+\frac{k_{f}}{\varphi \cdot\left(k_{0}-k_{f}\right)}$

where, $k_{\text {sat }}$ indicates the volume compression modulus of water-saturated rock, $k_{f}$ indicates the volume compression modulus of pore fluids, $k_{d r y}$ is the volume compression modulus of rocks under arid conditions, $k_{o}$ is the volume compression modulus of rock matrix mineral particles, and $\varphi$ represents the porosity.

In Eq. $1, k_{f}$ is calculated using Wood's Equation (Reuss average):

$$
\frac{1}{k_{f}}=\sum_{i=1}^{n} \frac{s_{i}}{k_{i}}
$$

where, $s_{i}$ is the volume factor and $k_{i}$ is the volume modulus.

For two-phase water-gas rocks, we have

$$
\frac{1}{k_{f}}=\frac{s_{w}}{k_{w}}+\frac{s_{g}}{k_{g}}
$$

where, $s_{w}$ indicates the water saturation, $s_{g}$ indicates the gas saturation, $k_{w}$ represents the volume modulus of water and $k_{g}$ represents the volume modulus of gas.

Then, the Vp and Vs can be calculated using the XuWhite model (1995) given in equations (4) and (5):

$$
\begin{aligned}
& V_{p s a t}=\left(\frac{k_{s a t}+\frac{4}{3} \mu_{s a t}}{\rho_{s a t}}\right)^{\frac{1}{2}} \\
& V_{\text {ssat }}=\left(\frac{\mu_{\text {sat }}}{\rho_{\text {sat }}}\right)^{\frac{1}{2}}
\end{aligned}
$$

where, $V_{p s a t}$ is the P-wave velocity of water-saturated rock, $V_{\text {ssat }}$ is the S-wave velocity of water-saturated rock, $\mu_{\text {sat }}$ is the shear modulus of fluid-saturated rock, and $\rho_{\text {sat }}$ is the density of fluid-saturated rock.

After calculating the elastic modulus of the rock-forming solid minerals, fluid-saturated rocks and dry rocks, Gassmann's Equation is adopted to calculate the volume modulus and shear modulus of fluid-saturated rocks. The P- and Swave velocities can be obtained using Eq. 4 and Eq. 5 and these model parameters. Fig. (2) shows the changes in Vp and Vs with water saturation, and Fig. (3) shows the changes in $\mathrm{Vp} / \mathrm{Vs}$ with water saturation.

As clearly shown in Fig. (2), the P-wave velocity decreases slightly with increasing water saturation when the water saturation is less than $82.5 \%$ and increases remarkably when the water saturation is greater than $82.5 \%$, whereas the S-wave velocity always decreases with increasing water saturation. $\mathrm{Vp} / \mathrm{Vs}$ increases rapidly when the water saturation is close to $100 \%$, indicating that small amounts of gas in water/oil saturated rock can lead to a drastic drop in the Pand S-wave velocity ratio (shown in Fig. (2) and Fig. (3)). This occurs because the small amount of gas mixed into the fluid results in significantly higher compressibility. As the gas saturation increases, the P-wave velocity gradually increases. This occurs because the influence of shrinking rock density exceeds that of the descending elastic modulus. According to Gassmann's theory, the shear modulus is irrelevant to rock saturation [6]. The density of water saturated rocks is greater than that of dry rocks, leading to slightly lower S-wave velocities [7]. The small amount of gas in this rock can cause a rapid drop in the P-wave velocity.

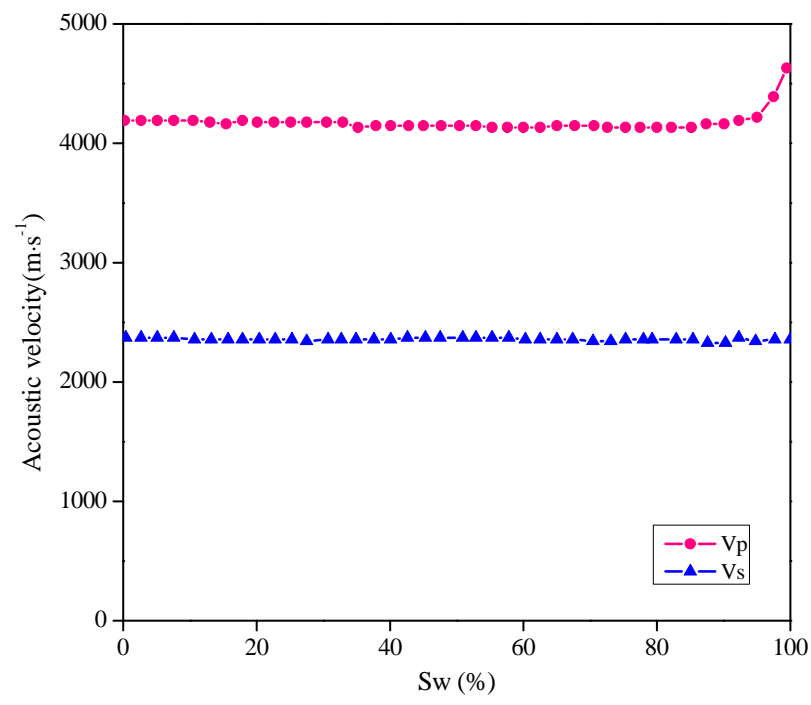

Fig. (2). Theoretical relationship of $\mathrm{Vp}$ and $\mathrm{Vs}$ to water saturation.

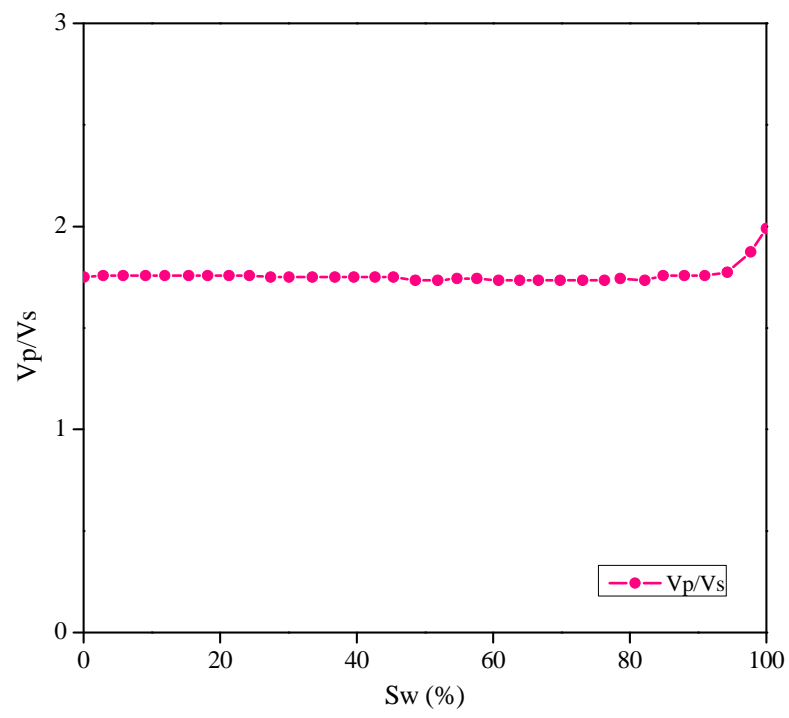

Fig. (3). Theoretical relationship of $\mathrm{Vp} / \mathrm{Vs}$ to water saturation.

Shi Xingjue (1995) noted that the water saturation of rocks has little effect on the S-wave velocity [8], and the 
effect of water saturation on the P-wave velocity occurs in two stages: when the water saturation is lower than a certain value, it has no impact on the P-wave velocity, but when it reaches a certain value, the velocity increased by approximately $30 \%$ with increasing water content. This is consistent with the theoretical modeling results.

\section{EXPERIMENTAL STUDY OF VP/VS AND WATER SATURATION}

\section{Testing Method}

In this study, 34 samples are taken from 15 wells in the Junggar Basin in China. The lithological characteristics of the rock specimens are listed in Table 1. There are 9 full diameter samples and 25 standard samples.

Ultrasonic transmission is used to measure the Vp and Vs of rock specimens under different pressures and gas saturations. We use an emissive sensor and a receiving sensor. The emissive sensor is used to send out ultrasonic waves, and the receiving sensor is used to receive the signal. The velocity of the sonic wave transmission is then calculated by dividing the specimen length with the wave's travel time.

Rock specimens are tested at normal temperature $\left(25^{\circ} \mathrm{C}\right)$ but under different confining pressures (1 $\mathrm{MPa}, 5 \mathrm{MPa}, 15$ $\mathrm{MPa}$ and $40 \mathrm{MPa}$ ).

The experimental procedure is as follows. First, place the dry rock sample into a container and vacuumize it for 5 hours (pressure up to $-0.1 \mathrm{MPa}$ ). Second, slowly introduce the formation water into the container until all of the samples are immersed in water and bubbles can be seen on the surfaces of the samples. Third, continue to vacuumize until all of the bubbles on the surface have vanished. Fourth, keep the samples quiescently standing for 12 hours, then take them out, wipe the surfaces dry, and weigh them with an electronic balance (precision $0.0001 \mathrm{~g}$ ). We assume, by this time, that the rock is $100 \%$ saturated with water.

The wave patterns are measured and recorded using water saturated rock specimens. After the measurement is completed, the rock specimens are placed into a dry vessel, where they are left to be air dried. The mass and water saturation of the rock specimens' decrease with the evaporation of water. During this process, the mass variations in the rock specimens are measured through a balance; the water content in this batch of rock specimens is different compared to that of the dry samples. The water saturation values are calculated by dividing the water content of each batch by a maximum (water content at $100 \%$ ) value. Vp and Vs are measured at each point where the water saturation is calculated, generating a relationship curve for wave velocity and saturation.

\section{Relationship Between P-Wave Velocity and Water Satu- ration}

The experiments are carried out under $25^{\circ} \mathrm{C}$ but with different pressures (1 $\mathrm{MPa}, 5 \mathrm{MPa}, 15 \mathrm{MPa}$ and $40 \mathrm{MPa}$ ). Fig. (6) to Fig. (9) show the P-wave velocities when using core samples. The red curve represents the gas-saturated case, the blue curve represents the water-saturated case, and the pink curve represents the $50 \%$ water-saturated case.
Fig. (4) gives P-wave velocities for gas and water saturated rock specimens under room temperature and pressure. Except for rock specimens 15, 16, 24, 28, 30 and 33, the Pwave velocities of all of the water saturated rock specimens are generally greater than those of gas saturated rocks, indicating that gas content may lower the P-wave velocity and that P-waves are more sensitive to gas. The porosities of rock specimens $15,16,24,28,30$ and 33 are very low, less than $4 \%$, and their permeabilities are also low. Simulated formation water is difficult to inject into pore spaces; thus, the P-wave velocities of $50 \%$ water-saturated, watersaturated and gas-saturated core samples barely change.

The experiments show that water saturated rocks have higher velocities than gas saturated rocks (see Fig. 5) under 5 $\mathrm{MPa}$. A greater $\mathrm{P}$-wave velocity is observed in most rocks when they are saturated in water compared to gas. However, the velocities of rock specimens 10, 15, 16, 24 and 28 are the same under water and gas saturated conditions.

Under $15 \mathrm{MPa}$, the P-wave velocities of rock specimens 10,28 , and 32 under $50 \%$ water saturation are close to those under full water saturation; in both cases, the velocities are much higher than those under gas saturation. For other rock specimens, gas saturation results in lower velocities than those under $50 \%$ and full water saturation. Overall, the velocities of gas saturated rocks are lower than those of $50 \%$ water saturated rocks. The velocities of $50 \%$ water saturated rocks are lower than those of fully water saturated rocks (see Fig. 6).

Under $40 \mathrm{MPa}$, the velocities of most water saturated specimens are greater than those under $50 \%$ water saturation, which are greater in turn than those under gas saturation. The velocities of rock specimens 10, 15, 16, 28, 29 and 30 under water saturation are close to those under $50 \%$ water saturation, but greater than those under gas saturation. Overall, all of the rock specimens under $40 \mathrm{MPa}$ at $25^{\circ} \mathrm{C}$ have greater velocities for full water saturation than those for $50 \%$ water saturation, which are greater in turn than those for gas saturation (see Fig. 7).

\section{Experimental Study of S-Wave Velocity and Water Satu- ration}

Fig. (8) and Fig. (9) show the S-wave velocities for gas and water saturated rock specimens under $1 \mathrm{MPa}, 5 \mathrm{MPa}, 15$ $\mathrm{MPa}$ and $40 \mathrm{MPa}$ at $25^{\circ} \mathrm{C}$.

Fig. (8) shows the S-wave velocities of gas and water saturated rock specimens under $1 \mathrm{MPa}$ at $25^{\circ} \mathrm{C}$. Most rock specimens have similar S-wave velocities for gas saturation, $50 \%$ water saturation and full water saturation, indicating that the $\mathrm{S}$-wave velocity is not sensitive to gas in volcanic rocks.

According to S-wave experiments performed at normal temperature and pressure, there is a relatively complicated pattern between the S-wave velocities of gas saturated and water saturated rock specimens. Except for rocks 1, 2, 4, 9, 11,22 and 34, there is little difference between the gas- and water-saturated rock specimens. Generally, the S-wave velocities of gas- and water-saturated rock specimens are very close. It is shown that experimental errors occur at normal temperature and pressure. The experimental precision of the rock specimens seems to be poorer than that of the samples due to the lack of homogeneity. 
Table 1. Lithological characteristics of the rock specimens in the Vp/Vs experiment.

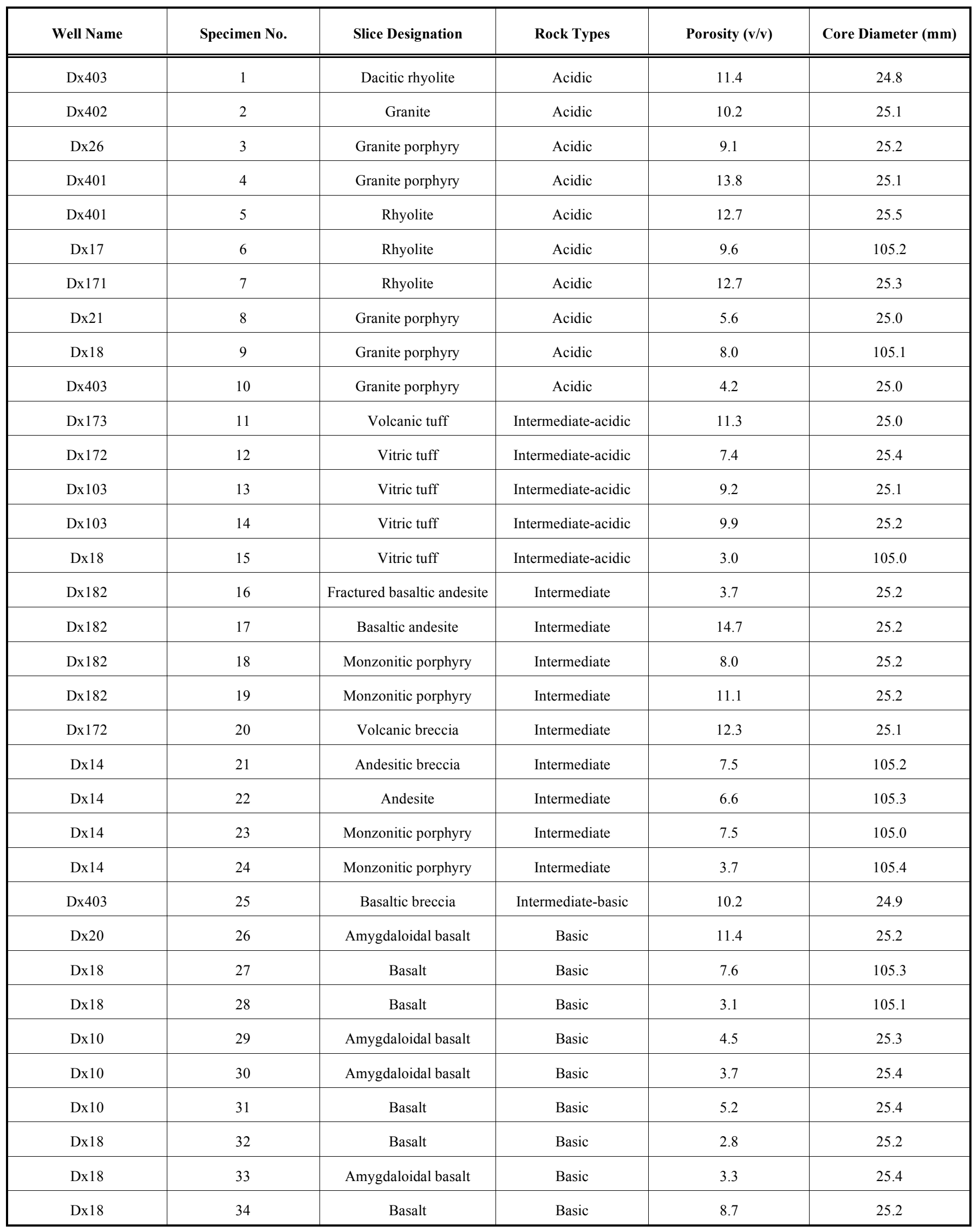




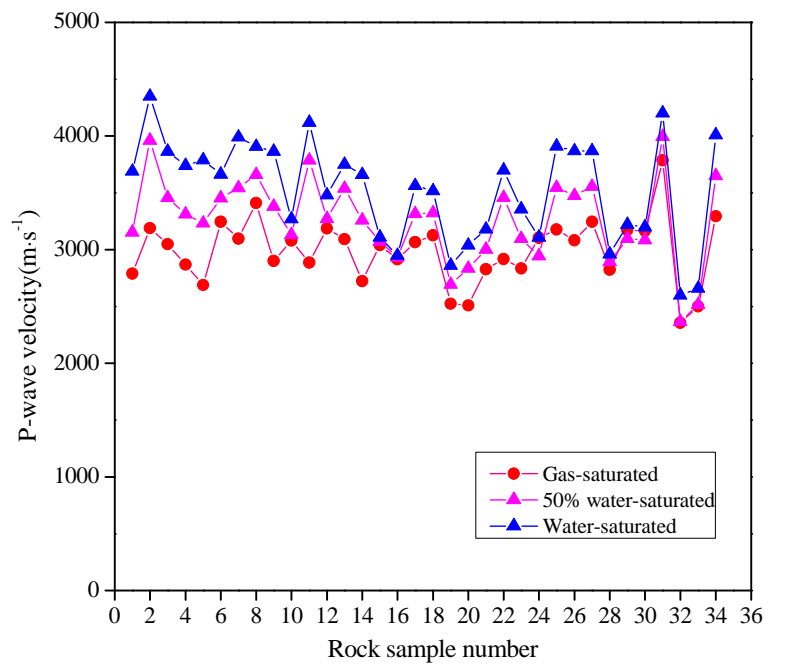

Fig. (4). P-wave velocities of gas- and water-saturated core specimens under $1 \mathrm{MPa}$ at $25^{\circ} \mathrm{C}$.

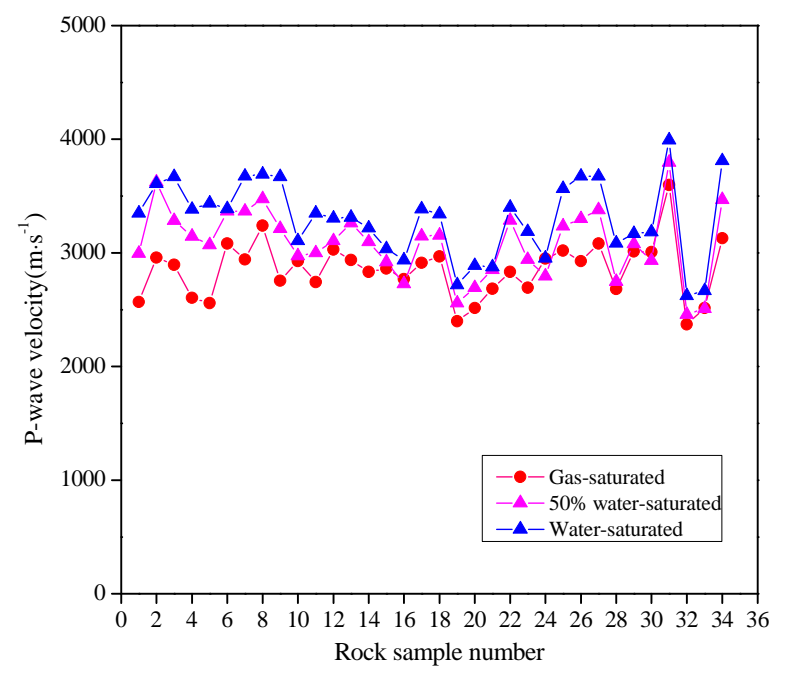

Fig. (5). P-wave velocities of gas- and water-saturated core specimens under $5 \mathrm{MPa}$ at $25^{\circ} \mathrm{C}$.

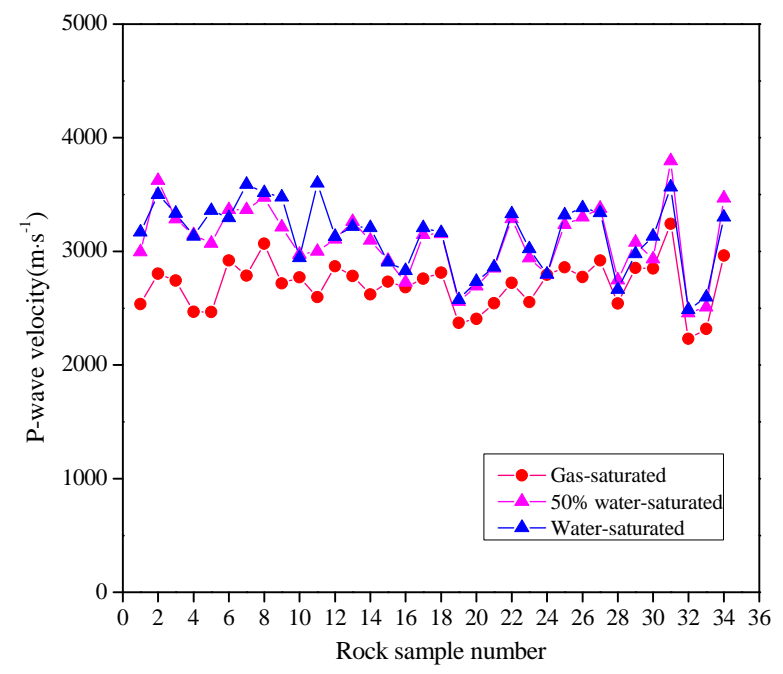

Fig. (6). P-wave velocities of gas- and water-saturated core specimens under $15 \mathrm{MPa}$ at $25^{\circ} \mathrm{C}$.

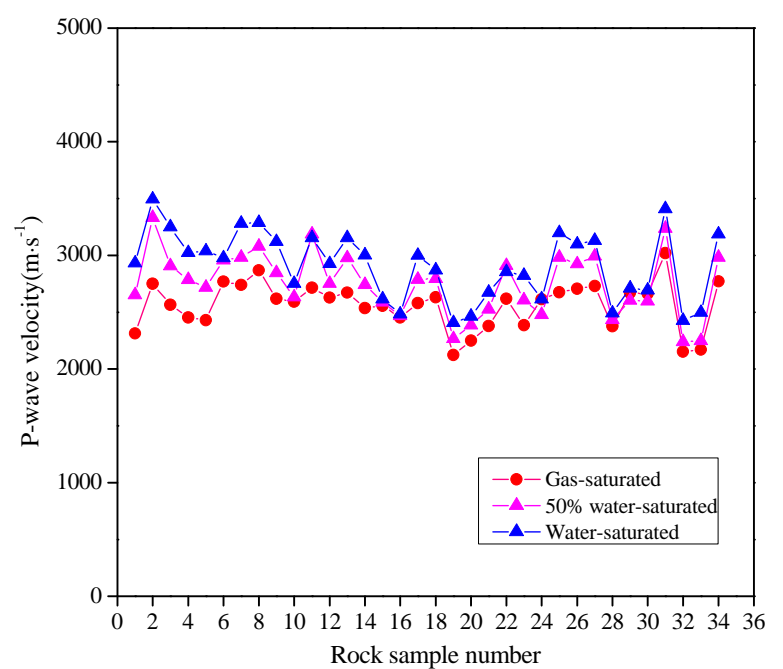

Fig. (7). P-wave velocities of gas- and water-saturated core specimens under $40 \mathrm{MPa}$ at $25^{\circ} \mathrm{C}$.

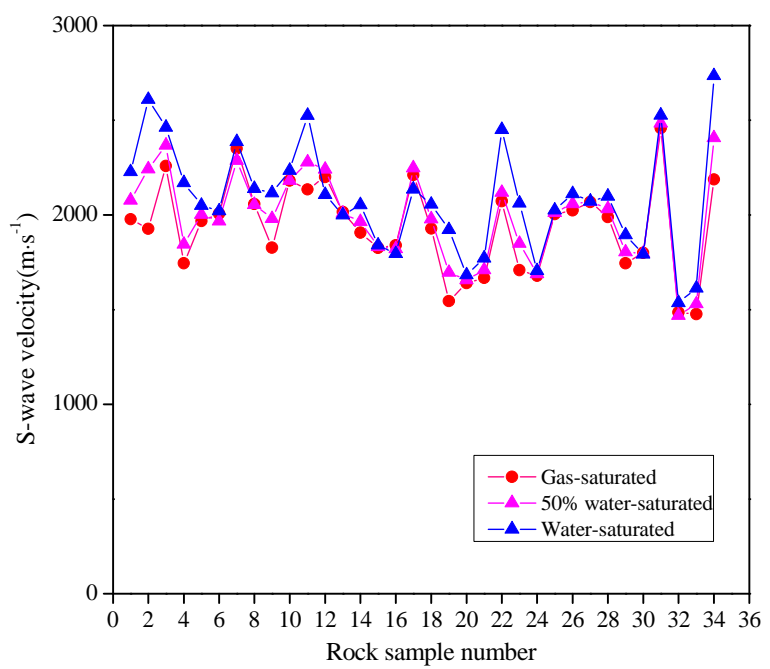

Fig. (8). S-wave velocities of gas- and water-saturated core specimens under $1 \mathrm{MPa}$ at $25^{\circ} \mathrm{C}$.

Under $5 \mathrm{MPa}$ (see Fig. 9), the S-wave velocities of the gas and water saturated samples are very similar, except for rock specimens 1, 2, 3, 4 and 34, indicating that the S-wave velocity is not sensitive to the properties or amount of fluid in the rocks.

Under $15 \mathrm{MPa}$ (see Fig. 10), the S-wave velocities of most rock specimens exhibit little difference under gas saturation, $50 \%$ water saturation and full water saturation. The velocities of rock samples 1, 2 and 34 are greater under gas saturation than under water saturation; the velocities of rock 6 under water saturation are less than under gas saturation and $50 \%$ water saturation; and the velocities of rock sample 14 under water saturation are greater than under $50 \%$ water saturation and gas saturation.

Under $40 \mathrm{MPa}$ (see Fig. 11), the S-wave velocities of all of the rock specimens except 2, 19 and 34 are almost the same under gas saturation, $50 \%$ water saturation and water saturation. 


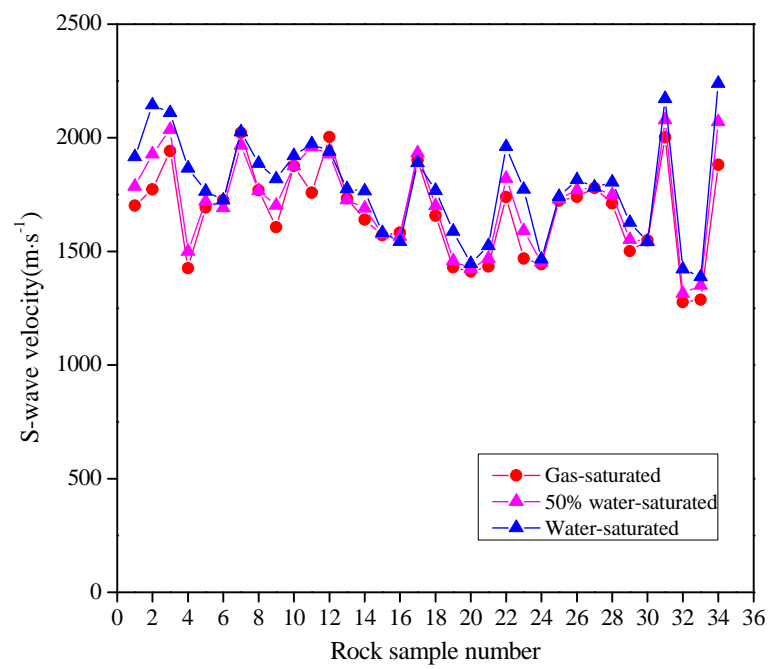

Fig. (9). S-wave velocities of gas- and water-saturated core specimens under $5 \mathrm{MPa}$ at $25^{\circ} \mathrm{C}$.

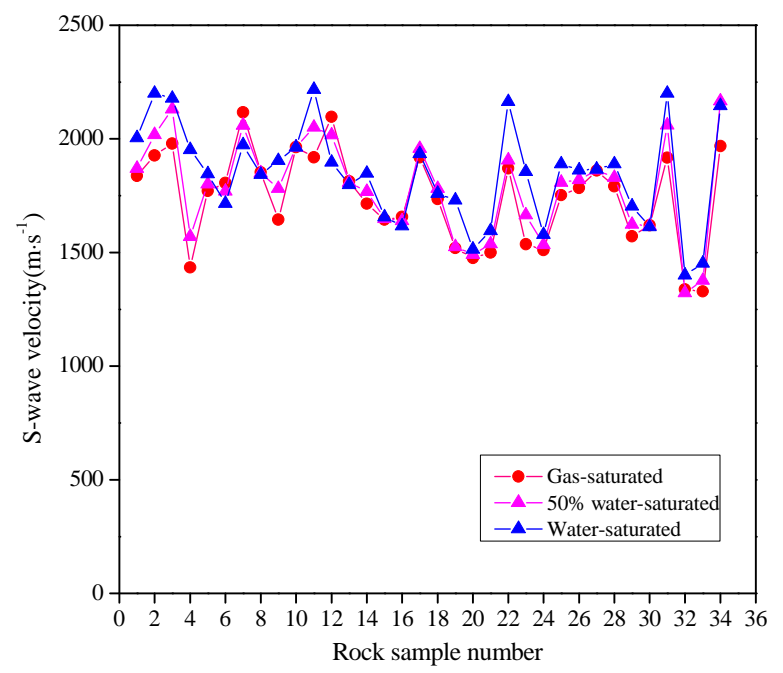

Fig. (10). S-wave velocities of gas- and water-saturated core specimens under $15 \mathrm{MPa}$ at $25^{\circ} \mathrm{C}$.

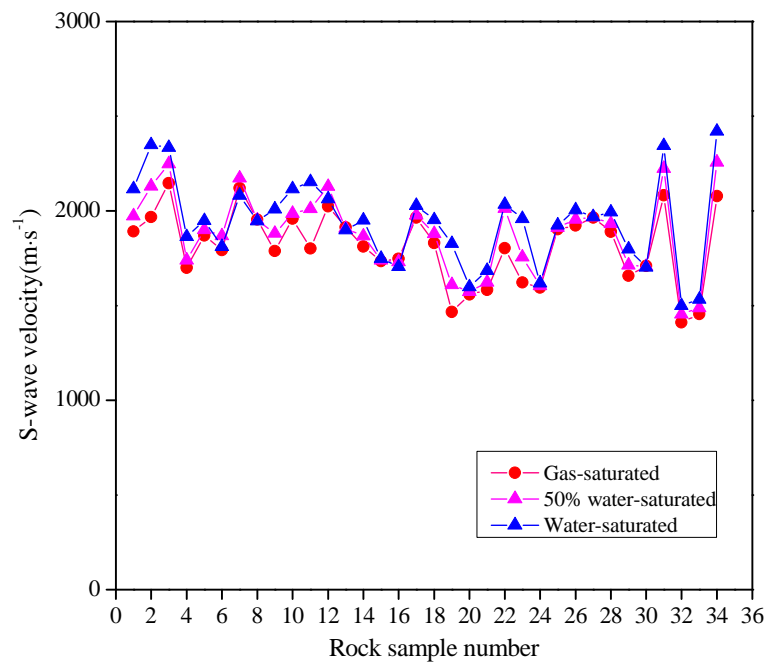

Fig. (11). S-wave velocities of gas- and water-saturated core specimens under $40 \mathrm{MPa}$ at $25^{\circ} \mathrm{C}$.
Based on our experiments, the P-wave velocity generally decreases as gas saturation increases, whereas the S-wave velocity decreases slightly or remains unchanged. Changes in wave velocity after the rock pores become water saturated may be caused by an increase in the active volume modulus of the rock. The shear moduli for gas and water are both 0 . Regardless of whether the rock is water saturated, its shear modulus remains invariant; thus, the P-wave velocity peaks for full water saturation $(\mathrm{Sg}=0)$; as $\mathrm{Sg}$ increases, the $\mathrm{P}$-wave velocity decreases gradually but slightly, while the S-wave velocity barely changes. The differences between individual experiments may be caused by different mineral and cement contents in the rocks. In addition, internal seams and caves, variously sized pores and the distribution of fluids in the rocks may affect the wave velocity.

\section{EXPERIMENTAL ANALYSIS OF THE VP/VS RATIO AND WATER SATURATION}

Theoretical analysis shows that the P-wave velocity decreases when there is a small amount of gas in a stratum, whereas the S-wave velocity is almost invariant, which makes the $\mathrm{Vp} / \mathrm{Vs}$ ratio more sensitive to types of fluids; the $\mathrm{Vp} / \mathrm{Vs}$ ratios of rocks containing water are higher than those of rocks containing gas (Shi Xingjue, 1995) [5].

Fig. (11) to Fig. (15) show the Vp/Vs ratios of core rocks under pressures of $1 \mathrm{MPa}, 5 \mathrm{MPa}, 15 \mathrm{MPa}$ and $40 \mathrm{MPa}$. From these figures, we notice that some difference exist between the $\mathrm{P}$-wave and S-wave velocities. The $\mathrm{Vp} / \mathrm{Vs}$ ratio for the same rock sample decreases with increasing gas saturation, which occurs because the P-wave velocity drops significantly when a water saturated formation contains gas, while the S-wave velocity barely changes. As a result, the $\mathrm{Vp} / \mathrm{Vs}$ ratio decreases. The $\mathrm{Vp} / \mathrm{Vs}$ ratios of a rock sample at the same saturation but different pressures are different, indicating the selectivity of acoustic wave frequencies by complex pore structures in volcanic rocks. The $\mathrm{Vp} / \mathrm{Vs}$ ratio is also affected by the fluid properties, lithology, porosity, effective stress and presence of cracks in the formation.

Fig. (12) shows the $\mathrm{Vp} / \mathrm{Vs}$ ratios of gas- and watersaturated rock specimens with different lithological characteristics at normal temperature and pressure. The $\mathrm{Vp} / \mathrm{Vs}$ ratios of gas-saturated rock specimens are generally lower than those of water saturated samples, with the exception of several rock specimens that have greater $\mathrm{Vp} / \mathrm{Vs}$ ratios under gas saturation than under water saturation. This is possibly caused by experimental errors and the core samples' low porosities.

The $\mathrm{Vp} / \mathrm{Vs}$ ratios of most core samples under full water saturation and $50 \%$ water saturation are greater than those under gas saturation (see Fig. (13) to Fig. (14)). In rocks with higher water saturation, the P-wave velocity is highly sensitive to gas content because tiny amounts of gas may sharply decrease the P-wave velocity. The P-wave velocity decreases with increasing gas content and water saturation. The water saturation of a rock has little effect on its S-wave velocity. As a result, the S-wave velocity decreases slowly with increasing water saturation.

A comparative analysis of $\mathrm{Vp} / \mathrm{Vs}$ ratios is made for rock specimens with gas saturations of $0 \%$ and $100 \%$. When $\mathrm{Sg}=0 \%$, the $\mathrm{Vp} / \mathrm{Vs}$ ratio is interpreted as a background value. For 34 rock specimens taken from the same formation, the 
$\mathrm{Vp} / \mathrm{Vs}$ ratio is generally small under gas saturation compared to under water saturation $(\mathrm{Sg}=0 \%)$. If gas-saturated rock is simulated as a gas reservoir and water-saturated rock as a water formation, the $\mathrm{Vp} / \mathrm{Vs}$ ratio progressively decreases with increasing gas content when the $\mathrm{Vp} / \mathrm{Vs}$ ratio of the same formation saturated with water is used as the background value; the more it decreases, the more likely the water formation transforms into a gas reservoir. The transformation can be interpreted by a progressive decrease in the Pwave velocity. This feature of $\mathrm{Vp}$ and $\mathrm{Vs}$ can be used to identify gas reservoirs during sonic logging. However, the development of seams and caves in volcanic rock formations and the uneven distribution of fluids therein confound the sonic wave responses of volcanic rocks.

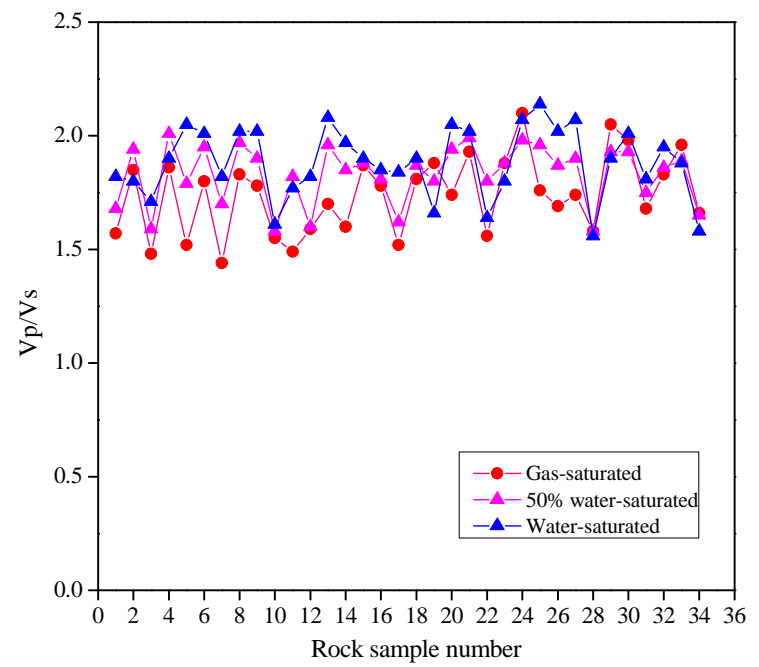

Fig. (12). Vp/Vs of cores under $1 \mathrm{MPa}$.

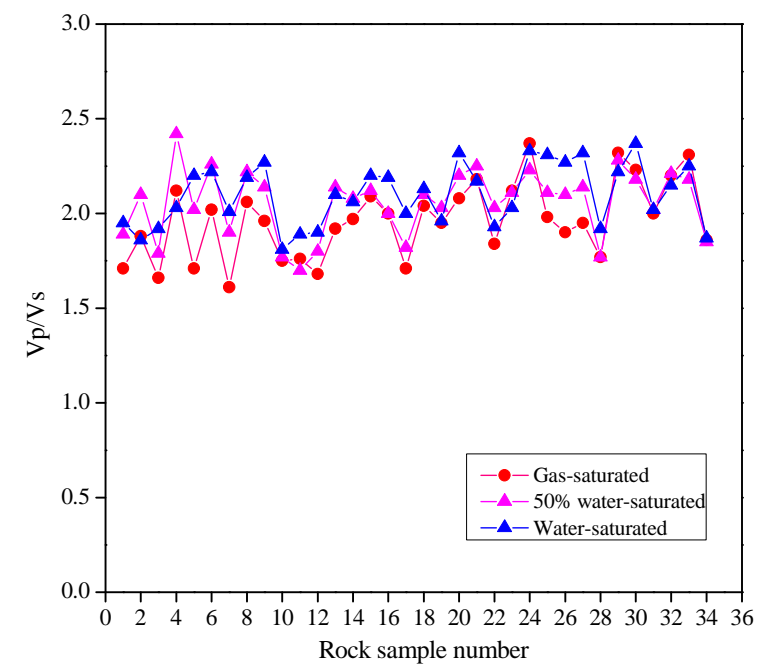

Fig. (13). Vp/Vs of cores under $5 \mathrm{MPa}$.

\section{COMPARISON BETWEEN THE THEORY AND EX- PERIMENTAL RESULTS AND DISCUSSION}

The theoretical simulation results show that the P-wave velocity reaches its lowest value when the water saturation increases from 0 to $100 \%$ (see Fig. (2), Fig. (3)). When the water saturation is less than this lowest value, the P-wave velocity slightly decreases with increasing water saturation. When the water saturation is greater than this lowest value, the P-wave velocity gradually grows with increasing water saturation. The S-wave velocity slightly decreases with increasing water saturation, an inverse relationship. According to Gassmann's theory, the shearing modulus has nothing to do with the saturation condition of rock pores; the density of wet rocks is greater than that of dry rocks, which slightly decreases the S-wave velocity. When the gas saturation is approximately $0 \sim 10 \%$, the values of P-wave velocity and $\mathrm{Vp} / \mathrm{Vs}$ significantly increase, which occurs because few gases are mixed into the liquid, significantly increasing overall compression ratio. When the gas saturation is higher than approximately $10 \%$, the $\mathrm{P}$-wave velocity and $\mathrm{Vp} / \mathrm{Vs}$ are not sensitive to gas saturation and do not change much with increasing gas saturation. It is clear that the S-wave and longitudinal wave velocities significantly decrease when the water layer has some gas [9].

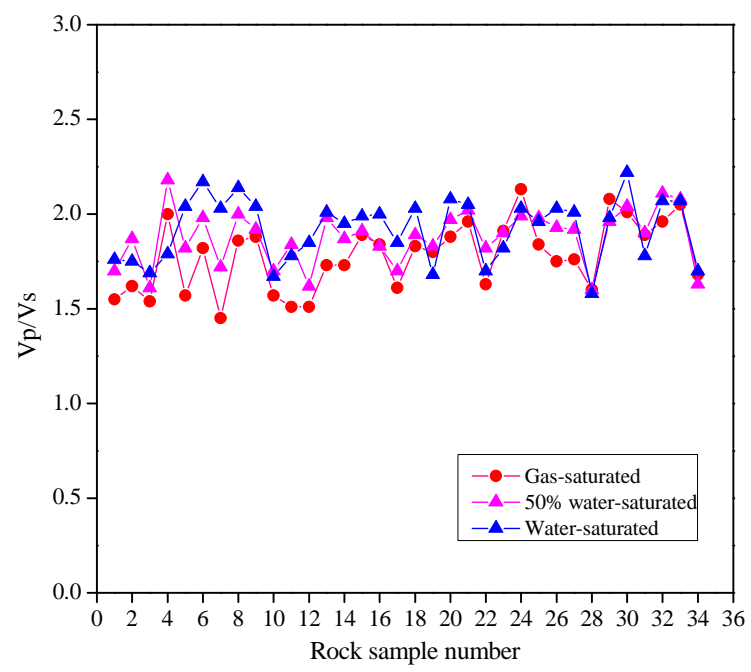

Fig. (14). $\mathrm{Vp} / \mathrm{Vs}$ of cores under $15 \mathrm{MPa}$.

The P-wave and S-wave velocity measurement results (see Fig. (4) - Fig. (11)) show that P-waves are sensitive to the gas content, and the P-wave velocity of saturated water is significantly greater than that of dry saturation (full of gas). Rocks with gas have significantly lower P-wave velocities, and S-waves are not sensitive to the gas content. The difference between the S-wave velocities for saturated gas and saturated water conditions is small, which is consistent with the theoretical knowledge. However, there are some samples where the S-wave velocity for saturated water is higher than under dry conditions, which is mainly caused by the low pressure. The experimental results show that the S-wave velocities of saturated rocks may be higher than those of dry rocks when the pressure is relatively low. The $\mathrm{Vp} / \mathrm{Vs}$ ratios of samples that are full of water are obviously greater than those of samples that are full of gas.

Theoretical simulations and experimental analysis show that the P-wave velocity is sensitive to the gas content; a small amount of gas can significantly decrease the P-wave velocity and $\mathrm{Vp} / \mathrm{Vs}$ ratio, while the S-wave velocity is not sensitive to the gas content. The differences in $\mathrm{P}$-wave veloc- 
ity between water layers and gas layers are small. The $\mathrm{Vp} / \mathrm{Vs}$ ratio is sensitive to the fluid type; the $\mathrm{Vp} / \mathrm{Vs}$ of a water layer is greater than that of a gas layer. Therefore, we can identify gas and water layers by this law. However, this type of discussion is so rough that it ignores the influence of porosity on the $\mathrm{Vp} / \mathrm{Vs}$ ratio. When the porosity is relatively small, it has limited influence on the $\mathrm{Vp} / \mathrm{Vs}$ ratio [10]. The porosity of volcanic rock reservoirs is small; as a result, we can ignore the influence of porosity on the $\mathrm{Vp} / \mathrm{Vs}$ ratio in this study. However, according to test results for different lithologies, the $\mathrm{Vp} / \mathrm{Vs}$ ratio can differ greatly for different lithologies. Therefore, the influence of lithologies cannot be ignored (see Fig. (12-15)).

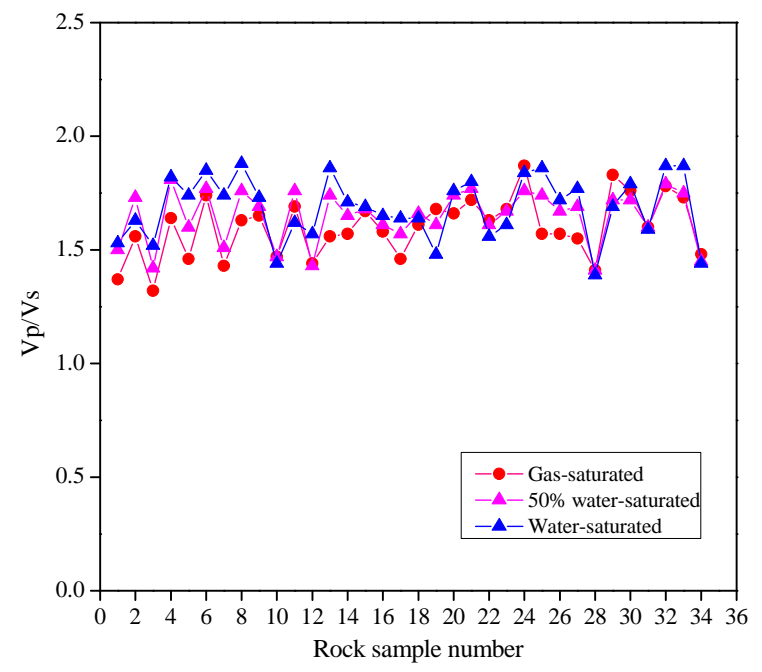

Fig. (15). Vp/Vs of cores under $40 \mathrm{MPa}$.

\section{EXPERIMENTAL ANALYSIS OF THE VP/VS RATIO, LITHOLOGY AND POROSITY}

Fig. (16) shows the relationship between the Vp/Vs ratio and porosity for different volcanic rock cores saturated with gas. The experimental results show that the relationship between the $\mathrm{Vp} / \mathrm{Vs}$ ratio and porosity has no obvious regularity. For porosities from $5 \%$ to $15 \%$, the change in the $\mathrm{Vp} / \mathrm{Vs}$ ratio is very small. Thus, when identifying gas reservoirs using the $\mathrm{Vp} / \mathrm{Vs}$ ratio, the influence of the pore fluid's properties can be ignored. At the same time, the experimental results show that the variation in the $\mathrm{Vp} / \mathrm{Vs}$ ratio is larger for the same lithology. The variation in the $\mathrm{Vp} / \mathrm{Vs}$ ratio for gassaturated basic volcanic rocks ranges between $1.41 \sim 1.87$, with a mean of 1.65 ; the variation in the $\mathrm{Vp} / \mathrm{Vs}$ ratio for gassaturated acidic lava is bigger, ranging between $1.32 \sim 1.74$, with a mean of 1.53 .

\section{USING THE VP/VS RATIO TO IDENTIFY GAS RES- ERVOIRS}

There are two types of methods for identifying fluid properties: electric and non-electric. The acoustic method falls into the non-electric category.

This method generally uses the properties of fluids to determine the "background value" of the properties (the Vp/Vs ratio in a water formation is usually deemed as the "background value"), and then the fluid properties are identified according to the dimensional relationships among the gas reservoir, water formation and background value.

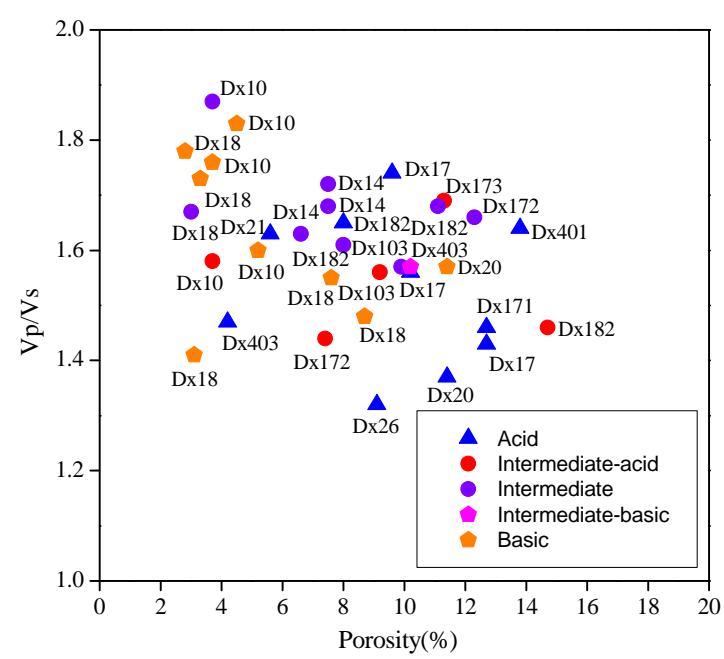

Fig. (16). Vp/Vs ratio and porosity cross plot of different volcanic rocks.

Based on our lab experiments, it is relatively difficult to determine by experiment the background value used to identify fluid properties, so it is necessary to utilize logging information to analyze the relationship between the $\mathrm{Vp} / \mathrm{Vs}$ ratios of various igneous rocks and the fluid properties in a formation. Our experiments also show that when the porosity of the formation is small, the $\mathrm{Vp} / \mathrm{Vs}$ ratio either does not change or changes slightly with changing porosity, but this is also affected by the fluid properties in the pore; the $\mathrm{Vp} / \mathrm{Vs}$ ratio decreases when the formation contains gas and increases when it contains water. For this reason, when using the $\mathrm{Vp} / \mathrm{Vs}$ ratio to determine fluid properties, the influence of pores on the ratio can be ignored; the background value can be taken from the $\mathrm{Vp} / \mathrm{Vs}$ ratio of the densified sections or gas water contact to identify fluids in the formation. When a stratum contains gas, the $\mathrm{Vp} / \mathrm{Vs}$ ratio should be smaller than this background value; when the stratum contains water, the ratio should be greater than the background value.

\section{Basic Rocks and Intermediate Rocks}

Based on the above experimental results, which are measured under $40 \mathrm{MPa}$ at $25^{\circ} \mathrm{C}$ to match the formation pressure of the work area's reservoirs, and the corresponding logging data, the conversion relationship between the $\mathrm{Vp} / \mathrm{Vs}$ ratios of the logging and experimental measurement values is calculated. Because resistivity logs are often used to identify gas reservoirs, a chart is established to identify gas reservoirs in basic and intermediate rocks using the resistivity logging data and the converted $\mathrm{Vp} / \mathrm{Vs}$ ratio, as shown in Fig. (17). This figure shows that the $\mathrm{Vp} / \mathrm{Vs}$ ratios of all of the points within a gas formation or water formation where gas is produced are generally less than the background value. In formations where both gas and water are produced, the $\mathrm{Vp} / \mathrm{Vs}$ ratio is less than background value, indicating that the $\mathrm{Vp} / \mathrm{Vs}$ ratio is always less than the background value as long as the stratum contains small amounts of gas. Thus, this method cannot distinguish between gas reservoirs and a formation 


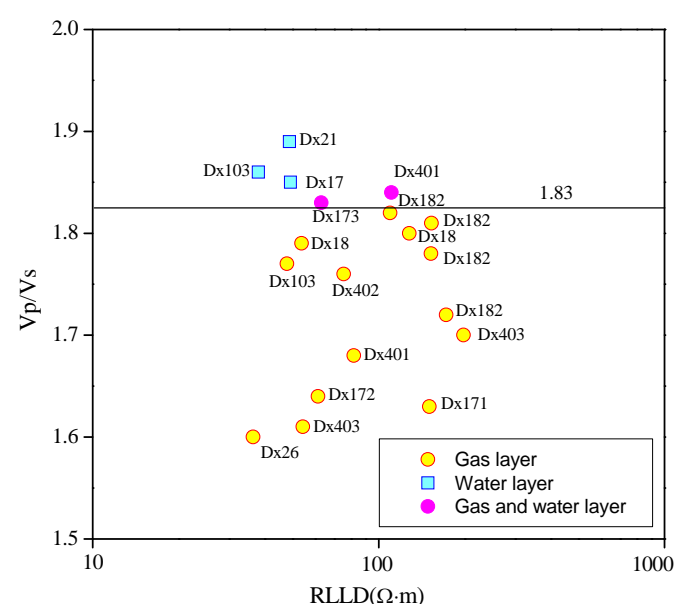

Fig. (17). Vp/Vs ratio and resistivity cross plot of basic and intermediate rocks.

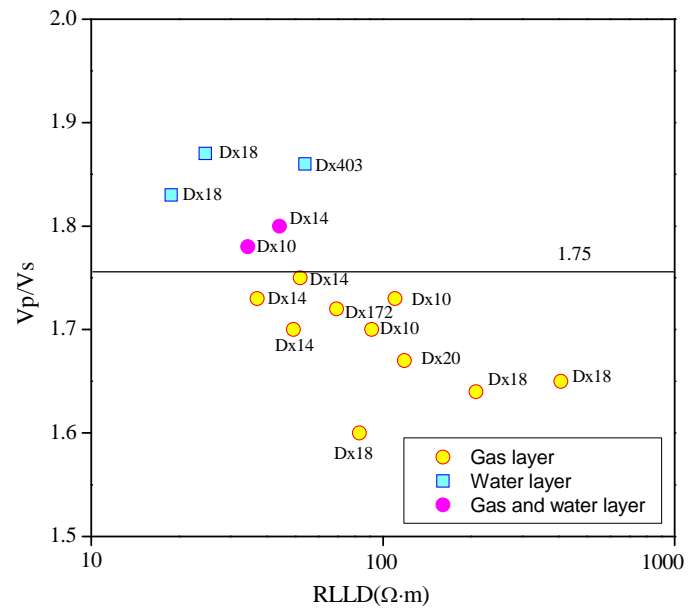

Fig. (18). Vp/Vs ratio and resistivity cross plot of acidic effusive rocks.

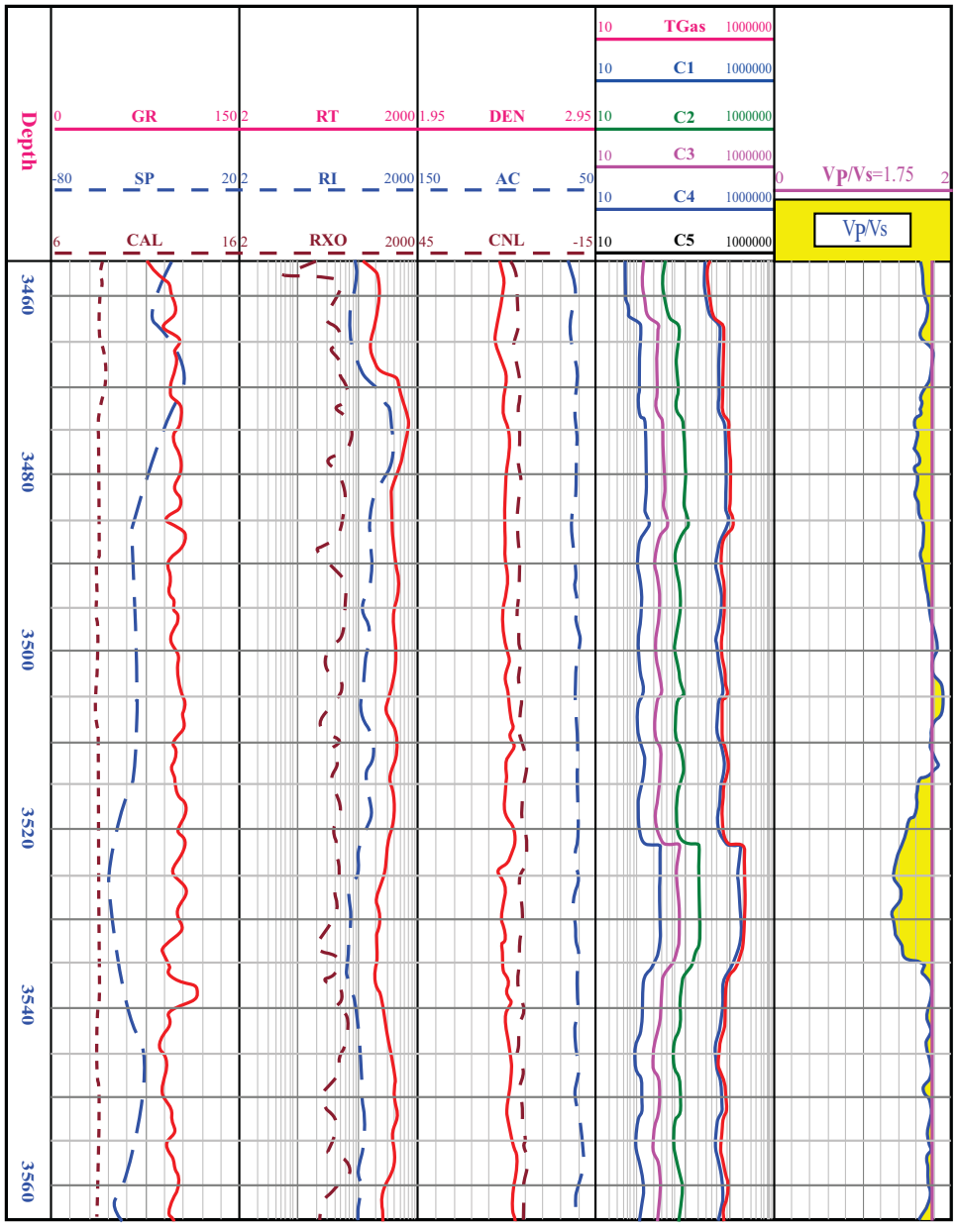

Fig. (19). Logging curve figure for identifying gas reservoirs using the Vp/Vs ratio in Well DX5.

containing both gas and water, consistent with the theoretical analysis, which states that the $\mathrm{Vp} / \mathrm{Vs}$ ratio significantly decreases when there is a small amount of gas in the stratum.

\section{Acidic Lava}

Based on the above method, which established a gas identification chart for basic volcanic rocks, a chart is also established to identify gas reservoirs in acidic lava, as shown in Fig. (18). The determined background value is 1.75. Fig. (18) shows that the $\mathrm{Vp} / \mathrm{Vs}$ ratios of all of the data points in gas formations and water formations that produce gas are less than the background value, whereas water formations have $\mathrm{Vp} / \mathrm{Vs}$ ratios greater than the background value. 


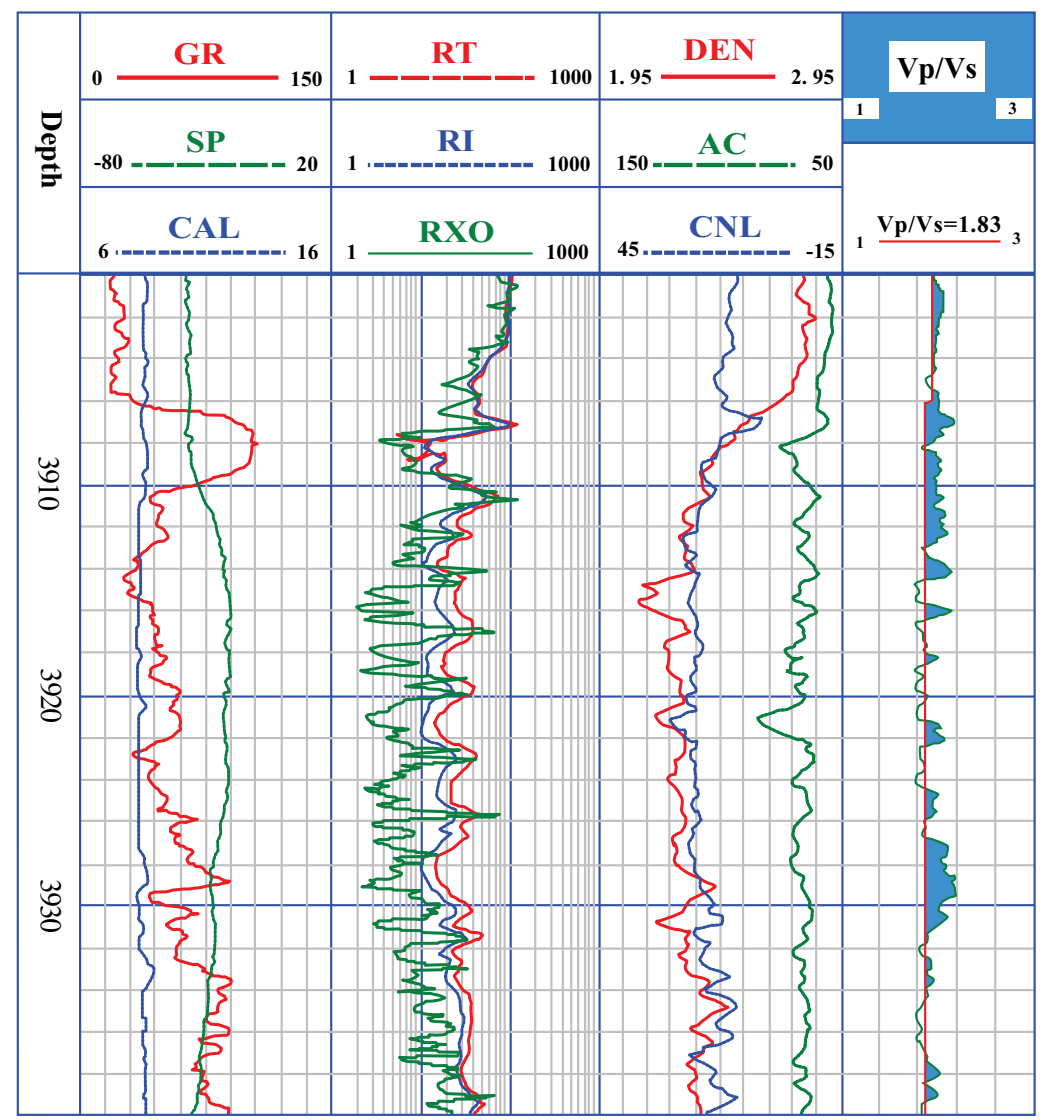

Fig. (20) Logging curve figure for identifying water layers using the Vp/Vs ratio in Well DX4.

\section{ANALYSIS OF APPLICATION CASES}

A 3460-3560 m deep reservoir in Well DX5 is characterized by high natural gamma rays and high resistivity. Its lithological nature is granite porphyry, and the rock type of the reservoir is acidic volcanic. With the $\mathrm{Vp} / \mathrm{Vs}$ ratio of the relatively densified section $(\mathrm{Vp} / \mathrm{Vs}=1.75)$ taken as the background value to identify the fluid properties, it is shown that the $\mathrm{Vp} / \mathrm{Vs}$ ratio is generally less than the background, and the P-wave velocity generally decreases, indicating that this feature is a gas reservoir. Well tests for oil at $3510-3530 \mathrm{~m}$ in this formation's section generate a daily gas production of $250,000 \mathrm{~m}^{3}$ (see Fig. (19)). The $\mathrm{Vp} / \mathrm{Vs}$ ratio is also less than the background value for formations that produce both gas and water at the same time. This indicates that the $\mathrm{Vp} / \mathrm{Vs}$ ratio is always less than the background value as long as the formation contains small amounts of gas. Therefore, this method cannot distinguish between gas-bearing formations and water-gas bearing formations. As a result, this method should be used in conjunction with other information, such as cracks, rock texture and structures, to identify gas formations in volcanic rocks.

A 3910-3940 m deep reservoir in Well DX4 is characterized by high natural gamma rays and high resistivity. Its lithological nature is basaltic breccia lava, and the rock type of the reservoir is basic volcanic. The P-wave velocity is generally higher according to the $\mathrm{Vp} / \mathrm{Vs}$ ratio, indicating that this feature is a water reservoir. A well test for oil at 3910$3930 \mathrm{~m}$ in this formation's section generates a daily water production of $25.83 \mathrm{~m}^{3}$ (see Fig. (20)).
The Carboniferous volcanic gas reservoir in the work area is identified using the method described in this paper, including 21 layers in which well tests for oil are identified, and the identification results of 18 layers are in accordance with the well test results. The coincidence rate is $86 \%$.

\section{CONCLUSION}

According to our lab experiments on volcanic rock specimens, the P-wave velocity generally decreases with increasing gas saturation, whereas the S-wave velocity barely changes. The $\mathrm{Vp} / \mathrm{Vs}$ ratio also decreases with increasing gas saturation. The $\mathrm{Vp} / \mathrm{Vs}$ ratios of different volcanic rocks vary, but the general rule is that the $\mathrm{Vp} / \mathrm{Vs}$ ratio at $\mathrm{Sg}=0 \%$ is greater than that at $\mathrm{Sg}=100 \%$. Our experiments, combined with theoretical analysis, conclude that the attenuation of P-waves can be used to identify gas reservoirs.

Practical effect analysis has shown that the $\mathrm{Vp} / \mathrm{Vs}$ ratio works well when used to identify gas and water formations in this region. However, the ratio does not work well when used to identify a reservoir that produces both water and gas. Considering that the sonic wave response of volcanic rocks is seriously affected by its internal structure, the $\mathrm{Vp} / \mathrm{Vs}$ ratio method proposed in this paper can be used as a reference method to identify gas reservoirs in volcanic rocks; in practical applications, it should be used in conjunction with other relevant parameters to achieve more accurate assessments. 


\section{CONFLICT OF INTEREST}

The authors confirm that this article content has no conflict of interest.

\section{ACKNOWLEDGEMENTS}

We would like to acknowledge the reviewers and the editor for their many helpful comments and suggestions, which significantly improved the manuscript. Thanks are also given to the key laboratory of science research project in Shaanxi province department of education (Grant NO: 14JS082; 14JS084) and special research project in Shaanxi province department of education (Grant NO: 2013JK0857) for their support during the completion of this paper.

\section{REFERENCES}

[1] F. Gassmann, "Elastic waves through a packing of spheres", Geophysics, vol. 6, pp. 673-682, 1951.

[2] W. Murphy, A. Reischer, "Modulus decomposition of compressional and shear velocities in sand bodies", Geophysics, vol. 58, pp. 227-239, 1993.
[3] Y.H. Zhang, C.W. Li, "Experimental Study of Relation between Pwave Characteristics and Water Saturation", Logging Technology, vol. 19 , pp. 6-10, 1995.

[4] O. Chardac, A. Brie, C. Chouker, "Correlations of shear vs. compressional in shaly sands and application to quick look hydrocarbon detection", Paper SPE 84205 presented at the SPE annual Conference and Exhibition, Denver, October 2003.

[5] H.L. Zhu, X.J. Liu, H. Liu, "Experimental research on effects of gas saturation on acoustic wave velocity of carbonate rock", Chinese Journal of Rock Mechanics and Engineering, vol. 30, pp. 2784-2789, 2011.

[6] W.W. Whitman, G.H. Towle, "The influence of elastic and density properties on the behavior of the Gassmann relation", The Log Analyst, vol. 33, pp. 500-506, 1992.

[7] M.J. Simon, A. Timothy, M. Clive, "The effect of degree of saturation on ultrasonic velocity and attenuation in sandstones. SEG67th, vol. 67, pp. 1023-1026, 1997.

[8] X.J. Shi, G.M. Xu, P. Jin, Z.G. Lu, W.Z. Liu, "Experimental Study of Effect of Rock Water Saturation on Vp/ Vs Ratio and Attenuation”, Chinese Journal of Geophysics, vol. 38, pp. 281-286, 1995.

[9] D.H. Han, I.B. Michael, "Gassmann's equationand fluid-saturation effects on seismic velocities", Geophysics, vol. 69, pp. 398-405, 2004.

[10] W. Roy, S. Gene, C. Lou, "The ratio Vp/Vs as a discriminant of composition for siliceous limestones", Geophysics, vol. 49, pp. 1850-1860, 1984.

Received: September 01, 2014

Revised: December 28, 2014

Accepted: December 30, 2014

(C) Liu and Zhao; Licensee Bentham Open.

This is an open access article licensed under the terms of the Creative Commons Attribution Non-Commercial License (http://creativecommons.org/licenses/by-nc/3.0/) which permits unrestricted, non-commercial use, distribution and reproduction in any medium, provided the work is properly cited. 